\title{
Impact of Health Care Delivery Utilization on Under-5 Child Mortality in Myanmar
}

\author{
Nyaung Tai*, Su Hlaing Tin Htut, Thiri Swe \\ Central Statistical Organization, Ministry of Planning and Finance, Nay Pyi Taw, Myanmar \\ Email address: \\ nyaungtai@gmail.com (N. Tai), suhlaingtinhtut@kgmail.com (S.H. T. Htut), thiriswe91@gmail.com (T. Swe) \\ ${ }^{*}$ Corresponding author
}

\section{To cite this article:}

Nyaung Tai, Su Hlaing Tin Htut, Thiri Swe. Impact of Health Care Delivery Utilization on Under-5 Child Mortality in Myanmar. International Journal of Health Economics and Policy. Vol. 4, No. 3, 2019, pp. 82-88. doi: 10.11648/j.hep.20190403.13

Received: July 21, 2019; Accepted: August 28, 2019; Published: September 10, 2019

\begin{abstract}
This paper examines the impact of healthcare delivery utilization on under-5 mortality in Myanmar. Reducing under-5 child mortality is the first target under the Sustainable Development Goal (SDG) Goal 3. In 2015, Myanmar registered anunder-5 mortality rate that was higher than the regional average. According to the World Health Statistics, Myanmar is a low-income country in the Southeastern Asian with high maternal deaths. This paper investigates the impact of the utilization of health care delivery on under-5 mortalities among states and region. In practice, all health factors are very important which relationships between utilization of health care delivery and under- 5 mortalities. These results give strong evidence of the success of the main findings. In spite of all variables were not statistically significant with the outcome variable were included in the multivariate analysis. The risk of child mortality was significantly higher for children of 4-5 birth order number (OR: 1.85; 95\% CI: $1.01-3.38 ; p=0.048)$ and above six or more birth order number (OR: $2.11 ; 95 \% \mathrm{CI}: 1.04-4.28 ; \mathrm{p}=0.039)$ respectively. Children who were treated by seeking health assistance that had reduced risk (OR: $0.06 ; 95 \% \mathrm{CI}: 0.01-0.29 ; \mathrm{p}=0.000)$ of childhood death compared with children who were no assistance of seeking health when children were no response. The risk of child mortality was significantly reduced for children whose mothers were accessible antenatal care facilities such as government hospital, private hospital, and mobile clinic (OR: 0.39; 95\% CI: $1.06-5.15$; $\mathrm{p}=0.000$ ). The paper efforts the relationship between utilization of health care delivery and under-5 child mortality by investigating of the socio-economic and demographic factors from first time Myanmar DHS (2015-2016). The main results highlighted the determinant of the main factors on under-5 child mortality among states and regions.
\end{abstract}

Keywords: Logistic Regression Method, Under-5 Mortality, Utilization of Health Care Delivery, Socio-Economic and Demographic Factors, States \& Regions, Myanmar

\section{Introduction}

Under-5 child mortality is of vital importance as one of the impact indicators of a country's Human Resource Development (HRD). Reducing U5MR that factor is stronger relationship between HDI and health improvement in countries [1]. According to the Global Health Observatory (GHO) data, 5.4 million children under age five died in 2017. Globally, under-five mortality rate has decreased by $58 \%$, from an estimated rate of 93 deaths per 1000 live births in 1990 to 39 deaths per 1000 live births in 2017. This is equivalent to 1 in 11 children dying before reaching age 5 in 1990, compared to 1 in 26 in 2017 [2]. In Myanmar, under-5
Mortality is 50 deaths per 1,000 live births. This is based on the first time of 2015-2016 Demographic and Health Survey (DHS) report [3].

Seventy percent of the population is living in rural area in Myanmar. The low utilization of Maternal and Child health $(\mathrm{MCH})$ services that patterns are unacceptably high in rural area [4].

The quality of health care, especially patient safety is essential to access all people and communities, everywhere in the world [5]. Hospitals and health systems are navigating the challenges and opportunities access to the living vulnerable rural and urban communities [6]. The public health care system is very important in ensuring that people will have access to quality health services. The sustainable development goal focus 
on the inadequate health worker performance in low and middle income for health requires access to quality essential healthcare services [7]. Improving child health requires adequate health services and sufficient skilled health workers.

\section{Methods}

\subsection{Data}

This paper uses the data from the 2015-2016 Myanmar Demographic and Health Survey (MDHS). The MDHS is a nationally representative population-based survey, which was implemented by the Ministry of Health and Sports (MOHS), the United States Agency for International Development (USAID), the Three Millennium Development Goal Fund (3MDG), and DHS Program. ICF provided technical assistance through The DHS Program, which assists countries in the collection of data to monitor and evaluate population, health, and nutrition programs.

MDHS includes four types of questionnaires namely, household questionnaire, woman's questionnaire, man's questionnaire, and biomarker questionnaire. It provides estimates at the national and regional levels, for urban and rural areas, and for each of Myanmar's 15 states and regions. MDHS provides information on fertility levels, marriage, fertility preferences, awareness and use of family planning methods, breastfeeding practices, nutrition, childhood and maternal mortality, maternal and child health, awareness and behavior regarding HIV/AIDS and other sexually transmitted infections (STIs), and other health-related issues such as smoking and knowledge of tuberculosis. A total of 12885 women were interviewed using the women's questionnaire.

This paper used the children's file (KR File), with a total of 4815 individual data on children age 0-59 months.

\subsection{Statistical Analysis}

This research attempts to estimate the overall impact of healthcare delivery utilization on under-5 child mortality. Since the independent variable is a binary variable, logistic regression is used to estimate the likelihood of under-5 mortality. The logistic regression model allows one to predict outcomes from a set of variables that may be continuous, discrete, dichotomous, or a mix of any of these. The Hosmer-Lemeshow test have described logistic regression focusing on its theoretical and applied aspect Logistic regression models the odds of success which is defined as the ratio of the probability of a success to the probability of a failure [8]. Hence, if $\mathrm{p}$ is the true success probability the odds of a success are $p /(1-p)$.

The adapted logistic regression model can be expressed as follows:

$$
\mathrm{Y}_{\mathrm{it}}=\beta_{0}+\beta_{1} \mathrm{X}_{\mathrm{it}}+\beta_{2} \mathrm{X}_{\mathrm{it}}+\beta_{3} \mathrm{X}_{\mathrm{it}}+\beta_{4} \mathrm{X}_{\mathrm{it}}+\beta_{5} \mathrm{X}_{\mathrm{it}}+\beta_{6} \mathrm{X}_{\mathrm{it}}+\beta_{7} \mathrm{X}_{\mathrm{it}}+\beta_{8} \mathrm{X}_{\mathrm{it}}+\beta_{9} \mathrm{X}_{\mathrm{it}}+\beta_{10} \mathrm{X}_{\mathrm{it}}+\varepsilon_{\mathrm{it}}
$$

\subsection{Descriptive Analysis}

MDHS 2015-2016 showed that the under-five mortality rate is 50 deaths per 1,000 live births. This means that 1 in 20 children does not survive until his or her fifth birthday. Childhood mortality is substantially higher in rural areas than urban areas. There are 80 under five deaths for every 1,000 live births in rural areas compared with 42 deaths in urban areas [3].

The Ministry of Health and Sport also is trying to reduce under-5 mortality among states and regions in Myanmar. Table 2 shows under- 5 mortality rate by region in Myanmar from several surveys.

Table 1. Under-5 mortality rate by states and regions.

\begin{tabular}{llll}
\hline Area & 2014 Census & 2015 (CSO) & 2015-2016 DHS \\
\hline Union & 71.8 & 65.3 & 50 \\
Urban & 46.3 & 43.8 & 42 \\
Rural & 78.8 & 72.1 & 80 \\
Kachin & 60.6 & 52.6 & 61 \\
Kayah & 69.7 & 62.7 & 50 \\
Kayin & 61.6 & 57.3 & 84 \\
Chin & 89.6 & 82.1 & 104 \\
Sagaing & 69.6 & 58.4 & 68 \\
Tanintharyi & 83.4 & 75.7 & 83 \\
Bago & 72.0 & 68.4 & 83 \\
Magway & 100.6 & 94.5 & 55 \\
Mandalay & 58.4 & 57.0 & 65 \\
Mon & 47.3 & 42.5 & 44 \\
Rakhine & 71.0 & 58.1 & 58 \\
Yangon & 51.0 & 46.5 & $(46)$ \\
Shan & 64.0 & 58.5 & 99 \\
Ayeyawady & 103.6 & 96.6 & 82 \\
Nay Pyi Taw & 63.8 & 59.3 & 79 \\
\hline
\end{tabular}

Source: The 2014 Myanmar Population and Housing Census Report, Vital Statistics Report, Central Statistical Organization-CSO (2014-15), Myanmar Demographic and Health Survey (2015-2016) Report 
Table 2 presents the outcome variable and the socio-economic and demographic factors of respondents.

Table 2. Outcome variable and factors of respondents.

\begin{tabular}{|c|c|c|c|}
\hline Factors & Respondents $(\%)(\mathrm{N}=4,815)$ & Factors & Respondents $(\%)(\mathrm{N}=4,815)$ \\
\hline Outcome variable & & \multicolumn{2}{|c|}{ Independent Variable } \\
\hline Under 5 child mortality & & \multicolumn{2}{|c|}{ Antenatal care facilities: Government hospital, private hospital, and mobile clinic } \\
\hline Alive & $4597(95.47 \%)$ & No & $1470(30.53 \%)$ \\
\hline Independent Variable & & \multicolumn{2}{|c|}{ Tetanus injection before birth } \\
\hline Sex of child & & No & $933(19.38 \%)$ \\
\hline Female & $2528(47.50 \%)$ & Yes & $3882(80.62 \%)$ \\
\hline Place of Residence & & 1 & $3034(63.01 \%)$ \\
\hline Urban & $1012(21.02 \%)$ & $2-3$ & $1760(36.55 \%)$ \\
\hline Rural & $3803(78.98 \%)$ & $4-5$ & $21(0.44 \%)$ \\
\hline Number of Birth order & & \multicolumn{2}{|c|}{ States \& Regions } \\
\hline$<1$ & $1549(32.17 \%)$ & Kachin & $353(7.33 \%)$ \\
\hline $2-3$ & $1951(40.52 \%)$ & Kayah & $379(7.87 \%)$ \\
\hline $4-5$ & $787(16.34 \%)$ & Kayin & $351(7.29 \%)$ \\
\hline $6+$ & $528(10.97 \%)$ & Chin & $479(9.95 \%)$ \\
\hline Big problem & $1549(32.17 \%)$ & Taninthayi & $329(6.83 \%)$ \\
\hline Not a big problem & $3266(67.83 \%)$ & Bago & $280(5.82 \%)$ \\
\hline Wealth quintile & & Magway & $270(5.61 \%)$ \\
\hline Poor & $2564(53.25 \%)$ & Mandalay & $268(5.57 \%)$ \\
\hline Middle & $870(18.07 \%)$ & Mon & $247(5.13 \%)$ \\
\hline Rich & $1381(28.68 \%)$ & Rakhine & $357(7.41 \%)$ \\
\hline Seeking health assistance & & Yangon & $248(5.15 \%)$ \\
\hline No & $4765(98.96 \%)$ & Shan & $351(7.29 \%)$ \\
\hline Yes & $50(1.04 \%)$ & Ayeyarwaddy & $314(6.52 \%)$ \\
\hline & & Naypyitaw & $241(5.01 \%)$ \\
\hline
\end{tabular}

Standard errors in parentheses; $* * * \mathrm{p}<0.01, * * \mathrm{p}<0.05, * \mathrm{p}<0.1$

\section{Results}

The findings assume that there is significant relationship between the utilization of health care delivery and under-5 child mortality, as shown in table 3.

Table 3. Outcome variable and factors of respondents' bivariate analysis and multivariate analysis of the relationship between utilization of health care and under-5 child mortality.

\begin{tabular}{|c|c|c|c|c|}
\hline $\begin{array}{l}\text { Factors } \\
\text { Sex of child }\end{array}$ & \multicolumn{2}{|c|}{ Bivariate analysis Odds Ratio (95\% CI) } & \multicolumn{2}{|c|}{ Multivariate analysis Odds Ratio (95\% CI) } \\
\hline Female (Reference) & 1 & & 1 & \\
\hline Male & 1.21 & $(0.83-1.75)$ & 1.16 & $(0.79-1.72)$ \\
\hline Rural (Reference) & 1 & & 1 & \\
\hline Urban & $0.61 *$ & $(0.37-0.99)$ & 1.06 & $(0.55-2.05)$ \\
\hline \multicolumn{5}{|l|}{ Number of Birth order } \\
\hline $2-3$ & 1.27 & $(0.81-1.99)$ & 1.10 & $(0.67-1.72)$ \\
\hline $4-5$ & $2.26 * * *$ & $(1.21-4.22)$ & $1.85 *$ & $(1.01-3.38)$ \\
\hline $6+$ & $2.94 * * *$ & $(1.61-5.36)$ & $2.11 *$ & $(1.04-4.28)$ \\
\hline \multicolumn{5}{|l|}{ Distance to health facilities } \\
\hline Big problem (Reference) & 1 & & 1 & \\
\hline Not a big problem & $0.61 * *$ & $(0.39-0.95)$ & 0.99 & $(0.65-1.49)$ \\
\hline \multicolumn{5}{|l|}{ Wealth quintile } \\
\hline Poor (Reference) & 1 & & 1 & \\
\hline Rich & $0.43 * * *$ & $(0.26-0.71)$ & 0.69 & $(0.39-1.24)$ \\
\hline \multicolumn{5}{|l|}{ Seeking health assistance } \\
\hline No (Reference) & 1 & & 1 & \\
\hline Yes & $0.12 * * *$ & $(0.03-0.51)$ & $0.06^{* * *}$ & $(0.01-0.29)$ \\
\hline \multicolumn{5}{|c|}{ Tetanus injection before birth } \\
\hline No (Reference) & 1 & & 1 & \\
\hline Yes & $0.66^{*}$ & $(0.43-1.03)$ & 1.25 & $(0.74-2.11)$ \\
\hline
\end{tabular}




\begin{tabular}{|c|c|c|c|c|}
\hline \multirow{2}{*}{$\begin{array}{l}\text { Factors } \\
\text { Antenatal care facil }\end{array}$} & \multicolumn{2}{|c|}{ Bivariate analysis Odds Ratio (95\% CI) } & \multicolumn{2}{|c|}{ Multivariate analysis Odds Ratio $(95 \% \mathrm{CI})$} \\
\hline & \multicolumn{4}{|c|}{ Antenatal care facilities: Government hospital, private hospital, and mobile clinic } \\
\hline No (Reference) & 1 & & 1 & \\
\hline Yes & $0.23 * * *$ & $(0.16-0.34)$ & $0.39^{* * *}$ & $(0.25-0.60)$ \\
\hline \multicolumn{5}{|c|}{ Number of Postnatal care visits } \\
\hline 1 (Reference) & 1 & & 1 & \\
\hline $2-3$ & $4.03 * * *$ & $(2.70-6.01)$ & $2.27^{* * *}$ & $(1.49-3.44)$ \\
\hline $4-5$ & $10.61 * * *$ & $(2.40-46.83)$ & $5.28 * *$ & $(1.75-15.92)$ \\
\hline \multicolumn{5}{|l|}{ States \& Regions } \\
\hline Kayah (Reference) & 1 & & 1 & \\
\hline Kachin & 1.30 & $(0.51-3.29)$ & 1.44 & $(0.56-3.71)$ \\
\hline Kayin & 1.72 & $(0.66-4.41)$ & 1.72 & $(0.66-4.46)$ \\
\hline Chin & $3.37^{* * *}$ & $(0.41-7.12)$ & $2.34 *$ & $(1.06-5.15)$ \\
\hline Sagaing & 1.44 & $(0.63-3.28)$ & 1.91 & $(0.78-4.64)$ \\
\hline Taninthayi & $2.30 *$ & $(0.83-6.40)$ & 2.05 & $(0.81-5.19)$ \\
\hline Bago & 1.36 & $(0.57-3.22)$ & 2.24 & $(0.92-5.49)$ \\
\hline Magway & 1.31 & $(0.53-3.25)$ & 1.92 & $(0.75-4.93)$ \\
\hline Mandalay & 1.88 & $(0.70-5.05)$ & $3.25^{*}$ & $(1.18-8.97)$ \\
\hline Mon & 1.23 & $(0.43-3.53)$ & 1.75 & $(0.61-4.95)$ \\
\hline Rakhine & 1.17 & $(0.48-2.83)$ & 1.00 & $(0.37-2.71)$ \\
\hline Yangon & 1.07 & $(0.33-3.44)$ & 2.22 & $(0.63-7.85)$ \\
\hline Shan & $2.87 * * *$ & $(1.26-6.53)$ & $3.24 * *$ & $(1.47-7.14)$ \\
\hline Ayeyarwaddy & 1.74 & $(0.76-4.01)$ & $2.62 *$ & $(1.09-6.28)$ \\
\hline Naypyitaw & 1.50 & $(0.57-3.99)$ & 2.08 & $(0.75-5.77)$ \\
\hline
\end{tabular}

Standard errors in parentheses; $* * * \mathrm{p}<0.01, * * \mathrm{p}<0.05, * \mathrm{p}<0.1$

According to the results of the bivariate analysis, there was a statistically significant association between child mortality and variables such as place of residence, number of birth order, distance to health facilities, wealth quintile, seeking health assistance, tetanus injections before birth, antenatal care facilities: Government hospital, private hospital, and mobile clinic, number of postnatal care visits, and region. However, sex of child was not significantly associated with child mortality. In spite of all variables were not statistically significant with the outcome variable were included in the multivariate analysis.

The risk of child mortality was significantly higher for children of $4-5$ birth order number (OR: 1.85 ; 95\% CI: $1.01-3.38 ; \mathrm{p}=0.048)$ and above six or more birth order number (OR: 2.11; 95\% CI: 1.04-4.28; $p=0.039$ ) respectively. Children who were treated by seeking health assistance that had reduced risk (OR: 0.06 ; 95\% CI: $0.01-0.29$; $p=0.000$ ) of childhood death compared with children who were no assistance of seeking health when children were no response. Maternal health-seeking behavior is associated with reducing under-5 child mortality [9].

The risk of child mortality was significantly reduced for children whose mothers were accessible antenatal care facilities such as government hospital, private hospital, and mobile clinic (OR: 0.39; 95\% CI: $1.06-5.15 ; \mathrm{p}=0.000$ ). The risk of child mortality was significantly increased for children whose mothers were visited postnatal care2-3 times (OR: $2.27 ; 95 \%$ CI: 1.49-3.44; $\mathrm{p}=0.000$ ) and $4-5$ times (OR: $3.25 ; 95 \% \mathrm{CI}: 1.18-8.97$; $\mathrm{p}=0.003$ ). This study finds that positive relationship between the accessible of visited postnatal care and under-5 mortality. The developing countries remain poor health quality and profitable healthcare that factors have effect on mortality [10]. Children born in Chin region (OR: 2.34; 95\% CI: $1.06-5.15$; $\mathrm{p}=0.035$ ), Mandalay region (OR: $2.34 ; 95 \%$ CI: $1.06-5.15 ; \mathrm{p}=0.035$ ), Shan region (OR: 3.24; $95 \%$ CI: 1.47-7.14; $\mathrm{p}=0.004$ ), and
Ayeyarwaddy region (OR: 2.62; 95\% CI: $1.09-6.28 ; \mathrm{p}=0.032$ ) respectively were significantly associated with increased risk of childhood death compared with children born in Kayah region.

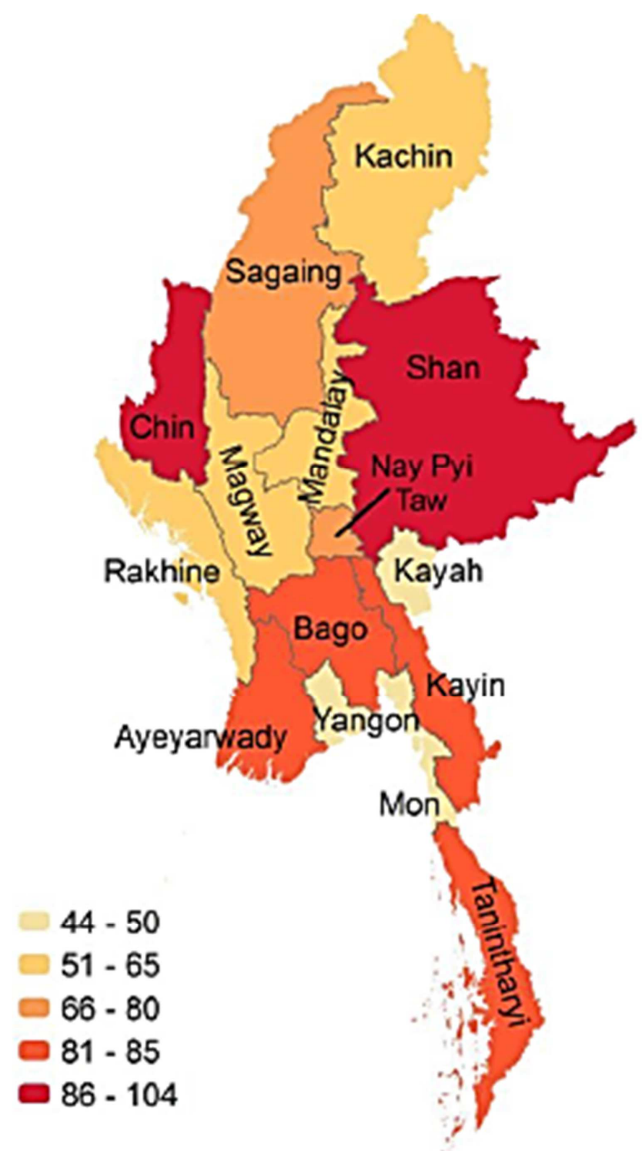

Figure 1. Under-5 mortality by states and regions.

Source: Myanmar Demographic and Health Survey (2015-2016) Report Note: Deaths per 1,000 live births in the 10-year period before the survey 


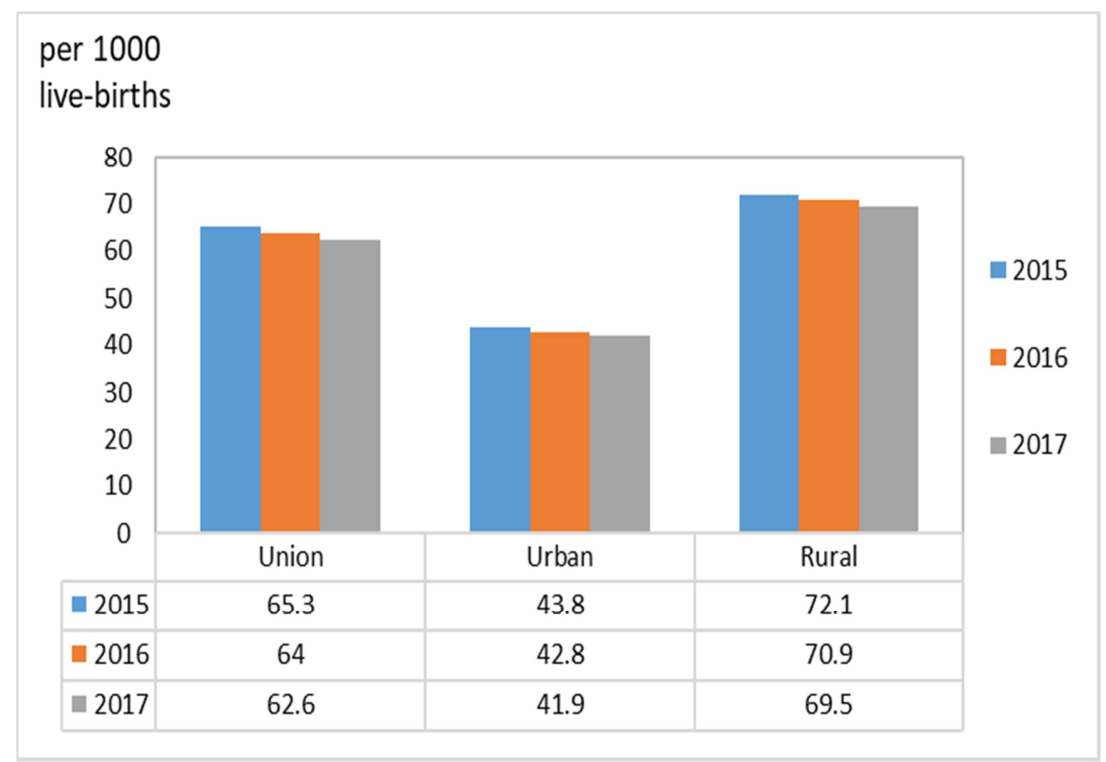

Figure 2. Under-5 mortality by Union, Urban, and Rural.

Source: Statistical Year Book (2018), Central Statistical Organization (CSO)

Note: Based on CRVS system, 2017 data refers projection number

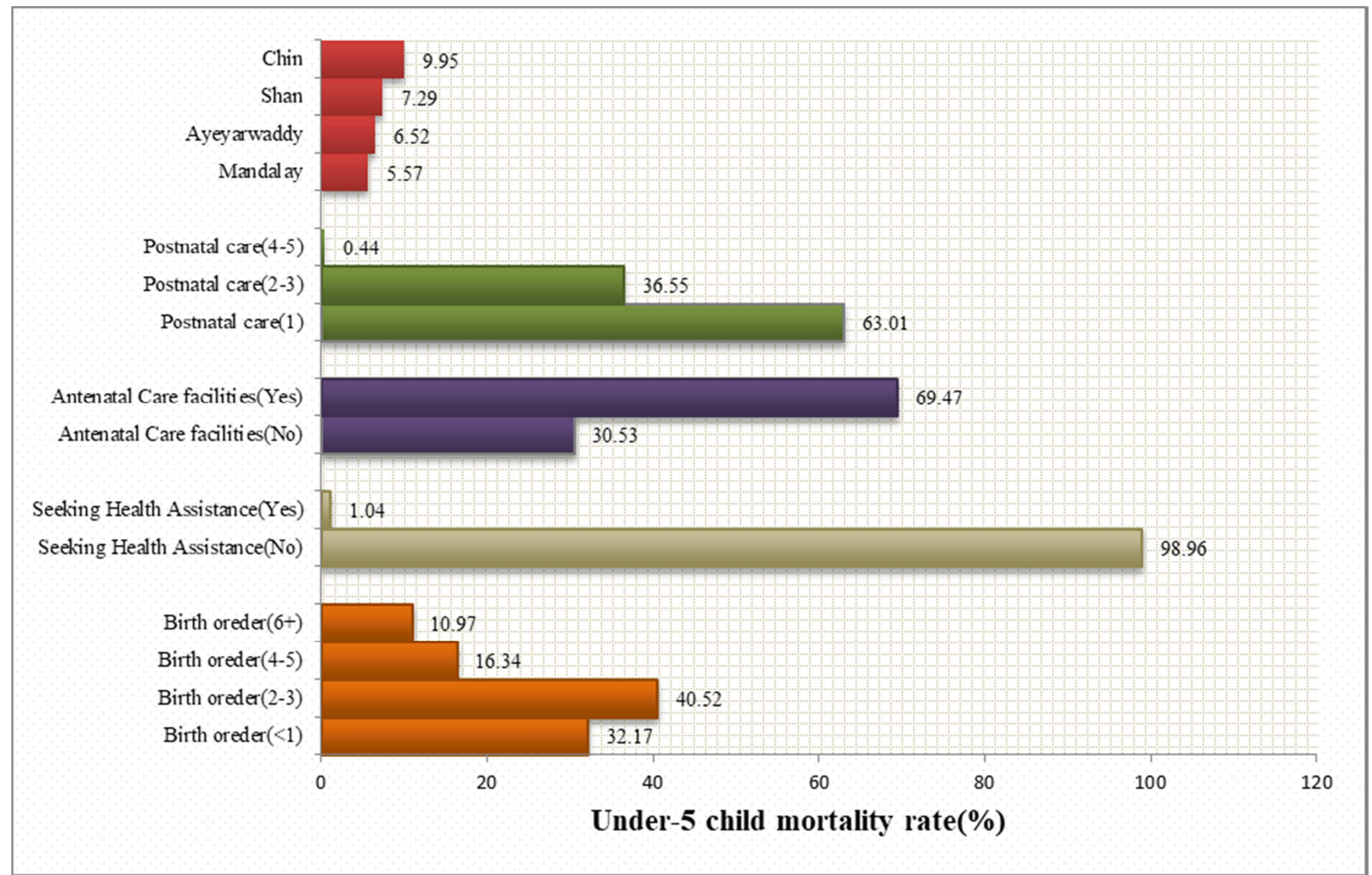

Figure 3. Impact of health care delivery utilization on under-5 child mortality among states and regions.

\section{Discussion}

This study finds that there is a significant association between utilization of health care delivery and under-5 mortality among states and regions.
(1) Birth Order Number

This result gives clear evidence for the impacts of birth order number on under-5 child mortality. According to the survival analytical methods' result, the risk of under-five death associated with the proceeding of the birth interval and 
the number of children ever born in Nigeria [11].

(2) Seeking Health Assistance

This result gives clear evidence for the impacts of health seeking assistance on under-5 child mortality. A possible reason is that women who are educated have more knowledge and good health seeking behavior. The interaction term of the parent who seeks health care delivery that reduces under-5 child mortality, which is negative significantly associated. There is significant association between health-seeking behavior and childhood mortality [12].

\section{(3) Antenatal Care}

This result gives clear evidence for the impacts of antenatal care facilities such as government hospital, private hospital, and mobile clinic on under- 5 child mortality. Furthermore, the interaction term of an individual child treated with antenatal care health facilities less likely to the odd of under-5 child mortality. According to the binary logistic regression result, this study found that the relationship between the effectiveness of antenatal care services and reducing neonatal mortality in Kenya [13]. WHO recommended antenatal care minimum eight times visit that associated with reducing perinatal mortality and improving women's knowledge care [14].

\section{(4) Postnatal Care}

This paper found that the risk of child mortality was significantly higher number of postnatal care visited. This could be access to the utilization of maternal and child health services. Otherwise, the reason will be the need to the improved skilled worker and health awareness. This study found that postnatal care was significantly negative associated with improving the continuum of care maternal and child health in Ratanakiri, Cambodia [15]. Skilled delivery of essential maternal and perinatal care practices that to reduce maternal and new-born injury [16].

(5) Region

That result shows that hilly regions such as Chin State and Shan State are more likely to under-5 child mortality. The reasons are health issues as poor community, poor roads, lack health care delivery, lack of health awareness, increasing children of women that impact will be increasing child mortality in hilly regions. Moreover, this study found that Mandalay Region is the third capital city as big urban area is more likely to under-5 child mortality. Because, according to the Myanmar Statistical Year Book 2016, the maternal mortality rate is higher in Mandalay region [17].

The finding suggests that maternal mortality is associated with the risk of child mortality. Besides, the logistic regression shows that the positive significantly associated between the individual under-5 children of Ayeyarwaddy Region and under-5 mortality. This region is faced natural disaster that impacts on the activity of socio-economic factors. In consequence, the difficult to access community, health facilities, wealth quintile, and education, motivation rehabilitation of mental and physical in the affected area as Ayeyarwaddy Region. According to the under-5 child mortality ranking statements, Chin State and Shan State are the highest range (86-104), Ayeyarwaddy Region is the second highest range (81-85), and Mandalay Region is the second lowest range (51-65) in 2015-2016 Demographic and Health Survey (DHS) report [3]. This paper investigates that impact of utilization of health care delivery on under- 5 mortality among states and region.

\section{Conclusion}

This study evaluates the impact of healthcare delivery utilization on under-5 child mortality among States and Regions. The logistic regression results show that the odds of under-5 mortality increases with increasing number of children. On the other hand, most of the parents are less interested in the utilization of health care delivery as their number of children increases. This implies that encouraging parent to seek their child in a health care is not enough. However, being a child of a woman with 4-5 birth order number and being a child of a woman with six or more birth order number, being a child of women accessible of antenatal care facilities, being a child of women utilization of postnatal care, being a child of a woman living in Chin, Shan, Mandalay, Ayeyarwaddy regions, being a child was were significantly associated with child mortality. In summary, finding results showed that strong evidence of the success of the main findings. Therefore, policy makers need to target these factors in their effort to reduce child mortality. The study has policy implications for the states and regions of functional health facilities within specified distance and improved quality of health care delivery. This study suggests that utilization of health care delivery as health facility-based delivery is a complex issue that requires further research using the qualitative approach to understand the impact of utilization of health care delivery on child mortality among states and region in Myanmar as well as explore the barriers to health care delivery for women.

\section{Acknowledgements}

First of all, we would like to thank Almighty God for his love and giving wisdom throughout our studies. We would like to thank USAIS/ICF for funding support. On the other hand, we would like to appreciate the Myanmar DHS fellows program and Ministry of Health and Sport (MOHS) for their guidance and help provided our research paper. Special gratitude goes to Dr. Kerry L. D. MacQuarrie, Dr. Elma Laguna, Dr. Jennifer Yourkavitch, and Mr. Khin Kyu, who turned our fractured thoughts into a solid viable utilization of health care on under-5 child mortality research idea and give comments and suggestions towards this work. Furthermore, we would like to express Ministry of Planning and Finance (MOPF) and Central Statistical Organization (CSO) for the great opportunity to let us study in this program for the health sector. Finally, we would like to thank our colleagues for their help, kindness, and having a good time together with them. 


\section{References}

[1] Yazdizadeh, B., et al., Impact of Health Research Systems on Under-5 Mortality Rate: A Trend Analysis. International journal of health policy and management, 2016. 6 (7): p. 395-402.

[2] World Health Organization. Under-five mortality. 2017; Available from: https://www.who.int/gho/child_health/mortality/mortality_und er_five_text/en/.

[3] Ministry of Health and Sports, I. C. F., Myanmar Demographic and Health Survey 2015-16. 2017: Nay Pyi Taw, Myanmar.

[4] Agunwa, C. C., et al., Determinants of patterns of maternal and child health service utilization in a rural community in south eastern Nigeria. BMC Health Services Research, 2017. 17: p. 17: 715 .

[5] World Health Organization, O. E. C. D., International Bank for Reconstruction and Development/The World Bank, Delivering quality health services: a global imperative for universal health coverage. 2018.

[6] Bhatt, J. and P. Bathija, Ensuring Access to Quality Health Care in Vulnerable Communities. Academic medicine. the Association of American Medical Colleges, 2018. 93 (9): p. $1271-1275$.

[7] Rowe, A. K., et al., Improving health worker performance: an ongoing challenge for meeting the sustainable development goals. BMJ, 2018. 362.
[8] Wikipedia, Hosmer-Lemeshow test. 2017.

[9] Chadoka-Mutanda, N. and C. O. Odimegwu, Maternal Health-Seeking Behaviour And Under-Five Mortality In Zimbabwe. Journal of Biosocial Science, 2017. 49 (3): p. 408-421.

[10] The Borgen Project, How to Gradually Improve Health in Developing Countries. 2017.

[11] Wegbom, A., I. D Essi, and V. Kiri, Survival Analysis of Under-five Mortality and Its Associated Determinants in Nigeria: Evidence from a Survey Data. 2019.

[12] DUSABE. J, Determinants Of Under-5 Mortality In Rwanda. 2016.

[13] Arunda, M., A. Emmelin, and B. O. Asamoah, Effectiveness of antenatal care services in reducing neonatal mortality in Kenya: analysis of national survey data Global health action, 2017. 10 (1) (1328796).

[14] The WHO Reproductive Health Library (RHL), WHO recommendation on antenatal care contact schedules. 2018.

[15] Kikuchi, K., et al., Postnatal care could be the key to improving the continuum of care in maternal and child health in Ratanakiri, Cambodia. PLOS ONE, 2018.

[16] Dohbit, J., et al., Improving Maternal Health: The Safe Childbirth Checklist as a Tool for Reducing Maternal Mortality and Morbidity. 2019.

[17] Ministry of Planning and Finance, C. S. O., Myanmar Statistical Year Book. 2016, Naypyitaw, Myanmar. 